\title{
La literatura infantil y la correspondencia: un intercambio entre adultos que acompañan la educación inicial
}

\author{
Children's Literature and Correspondence: An Exchange among Adults \\ Who Accompany Initial Education \\ Alejandra Cardona Castrillón* \\ (D) https://orcid.org/0000-0001-5109-9512 \\ Luisa Fernanda Acosta Castrillón** \\ (iD https://orcid.org/0000-0002-4528-2318
}

Tipo de Artículo: Informes de Investigación y ensayos inéditos

Doi: 10.17533/udea.unipluri.20.2.020

Cardona Castrillón, A., \& Acosta Castrillón, L. F. (2020). La literatura infantil y la correspondencia: un intercambio entre adultos que acompañan la educación inicial.Uni-Pluriversidad, 20(2). e20202020. doi:

10.17533/udea.unipluri.20.2.020

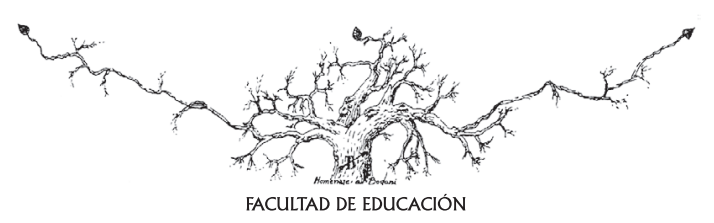

Recibido: 2020-03-25 • Aprobado: 2020-12-22

* Licenciada en Pedagogía Infantil. Especialista en Gerencia Educativa. Magíster en Educación. Estudiante de Doctorado en Ciencias de la Educación. Docente de la Universidad de Antioquia y Tutora del programa Todos a Aprender. Email: jeidy.cardona@udea.edu.co

** Licenciada en Pedagogía Infantil. Magíster en Educación. Estudiante de Doctorado en Educación. Docente de la Secretaría de Educación de Bello-Antioquia y de la Universidad de Antioquia.

Email: fernanda.acosta@udea.edu.co 


\title{
Resumen
}

Este artículo presenta los resultados de la investigación: La literatura infantil y la correspondencia: un intercambio entre adultos que acompañan la educación inicial, la cual tuvo como objetivo promover la literatura como una experiencia en la educación inicial a partir del género epistolar. El enfoque fue (auto)biográfico narrativo y orientó la escritura de siete cartas sobre la experiencia literaria de las investigadoras. La conversación, la lectura y el intercambio y reconocimiento de saberes fueron medulares para los resultados alcanzados. En el desarrollo de la propuesta participaron 25 maestros de educación básica primaria del Área Metropolitana. Los hallazgos representativos se organizaron en tres líneas: la investigación biográfica y narrativa: "un acontecimiento del ser"; la enseñanza de la lectura como un desafío para la escuela; el género epistolar como recurso reflexivo y formativo en la práctica de los maestros. Al final del artículo se comparten algunas conclusiones que dan lugar a nuevas preguntas y caminos de indagación.

Palabras clave: narrativa (auto)biográfica, experiencia, literatura infantil, género epistolar.

\begin{abstract}
This article presents findings of the research project Children's Literature and Correspondence: An Exchange among Adults Who Accompany Initial Education. The project aimed at promoting literature as an experience in initial education based on the epistolary genre. The approach was (auto) biographical narrative and guided the writing of seven letters about the literary experience by the researchers. Conversation, reading, and the exchange and recognition of knowledge were central to achieve the results. 25 teachers at basic primary school in the Metropolitan Area participated in this proposal. Main findings were organized in three lines: biographical and narrative research: "an event of being"; teaching reading as a challenge for the school; and epistolary genre as a reflective and educational resource in the teachers' performance. At the end, some conclusions that provide new questions and paths of inquiry are shared.
\end{abstract}

Keywords: (auto)biographical narrative, experience, children's literature, epistolary genre. 


\section{INTRODUCCIÓN}

La investigación se desarrolló en el año 2019 en el marco de la IV convocatoria de innovaciones didácticas del Centro de Investigaciones Educativas y Pedagógicas (CIEP) de la Universidad de Antioquia. La apuesta fue reflexionar sobre la experiencia que se produce en los entornos de educación inicial que acompañan el cuidado de los niños y las niñas a través de la literatura infantil. Las investigadoras fueron un grupo de maestras que coincidieron en un interés particular: generar provocación por la lectura desde los ambientes educativos y ofrecer condiciones de posibilidad a partir de las sensaciones, referencias e imágenes que ofrecen los libros, con la claridad de que "la experiencia de lectura, si es un acontecimiento, no puede ser causada [...] lo único que puede hacerse es cuidar de que se den determinadas condiciones de posibilidad" (Larrosa, 2003, p.40).

En el recorrido de la investigación surgieron preguntas que implicaron decisiones pedagógicas y metodológicas sobre la forma de aproximar a los niños y niñas a la literatura. ¿Cómo suscitar interés por los libros y la lectura? ¿cómo hacer de la lectura una experiencia? ¿qué lugar ocupan los adultos frente a la experiencia literaria que tienen los niños en sus primeros años? ¿cuáles son las estrategias que aportan interés por la lectura? Estos fueron algunos interrogantes que se construyeron durante la formulación del proyecto de innovación didáctica y que incentivaron el análisis. No obstante, este artículo no se orienta hacia la problematización de estas preguntas. La apuesta que nos convoca es exponer las experiencias (auto) biográficas construidas en relación con los modos de significar la disposición a la acogida de la vida de los niños y de las niñas a través de las palabras que ofrece la literatura infantil por parte de maestros y adultos.

En la revisión de antecedentes sobre las formas en que la literatura infantil acompaña el oficio del maestro en la educación inicial, encontramos autores que desde diferentes enfoques abordan las implicaciones de estos materiales en las prácticas de cuidado infantil. Dentro de los referentes de política pública se encuentra la propuesta de las actividades rectoras, donde el Ministerio de Educación Nacional (2014) sitúa el lugar de la lengua -oral y escrita- y literatura en la educación inicial como:

El arte que expresa la particularidad humana a través de las palabras, [...], puesto que el desafío principal que se afronta durante la primera infancia es tomar un lugar en el mundo de la cultura, es decir, reconocerse como constructor y portador de significado. (p.14)

Lo anterior pone de manifiesto que la literatura configura subjetividades porque, además de presentar una mirada sobre el mundo, las emociones, lo otro y los otros, se ha construido como acervo cultural; los niños y las niñas generan un juego de transformación sobre las experiencias previas y venideras.

Igualmente, referentes como Rodari (1980), Colomer (1998) y Petit $(2000 ; 2008$; 2009) sitúan en sus investigaciones de manera crítica que, además de la instrumenta- 
lización de la literatura con fines educativos y/o moralizantes, la apropiación de la literatura trasciende los fines pedagogizantes e introduce a los niños y niñas en el mundo de lo simbólico y lo habilita en la palabra para lenguajear aquello que lo habita o comprende que habita en otros.

Con respecto a la elección metodológica, el enfoque (auto)biográfico narrativo permitió suscitar las memorias y las experiencias literarias de las investigadoras, las cuales se materializaron en la escritura de siete cartas que expresan la sensibilidad de acompañar la vida de los niños y las niñas, como lo dice Yolanda Reyes (Canal Capital, 2021), a través de abrazos de palabras, imágenes y provocación por la cultura. Las cartas se constituyeron en una estrategia que buscó inspirar y motivar prácticas sensibles que cuidaran el vínculo educativo y acompañaran el mundo cotidiano de la infancia, reconociendo que los manuales orientadores que buscan responder de manera homogenizante a cómo desarrollar prácticas lectoras desde la infancia, se agotan en la presentación de fórmulas. En su lugar, las experiencias presentes en los relatos (auto)biográficos de estas cartas ofrecen pistas de que lo cotidiano nos enseña que allí, donde la obligatoriedad de la adquisición del código lectoescritor fracasa, los gestos, las miradas, la disposición de los objetos y la cercanía de las palabras forman lectores y generan un espacio en el tiempo para ingresar al mundo de lo simbólico. La escritura (auto)biográfica es:

Una herramienta que puede permitirnos aprender de nosotros mismos o de las vidas de maestros/as y profesores/as que han tejido sus propias trayectorias y que nos han dejado su testimonio como ejemplo de vidas en las que la educación ha ocupado un papel más que relevante en muchas ocasiones. (Ocaña, 2010, p.7)
Con esto, las situaciones de lectura en las que están inmersos los personajes de la correspondencia aluden a interacciones entre adultos y niños en las que hubo una transmisión de la cultura o del código lector a partir de los libros. Incluso, se narran situaciones donde no había otra intención distinta que leer, lo que amplía el panorama para pensar la lectura como algo que no está sujeto a las intencionalidades pedagógicas, sino que aparece en las prácticas cotidianas desde la experiencia.

Para el diseño de la correspondencia se partió de grupos de discusión entre las investigadoras en los cuales se identificaron momentos, situaciones y recuerdos relacionados con su experiencia literaria, que se valoran en el presente como imágenes educativas que motivaron a la lectura y que persisten en la memoria como eventos significativos que propiciaron una relación creativa con las narraciones leídas. Esta rememoración es la que aparece en las historias recreadas desde el género epistolar que retoma elementos cercanos a la conversación, la cual está dirigida a los adultos que se consideran referentes para los niños y niñas e incorporan un "tono afectivo" (Soto, 1996). Así, se busca que los lectores recuerden sus propias experiencias en relación con la lectura y, a partir de ello, innoven en sus prácticas educativas actuales.

Las cartas fueron compartidas con 25 maestros de educación básica primaria del Área Metropolitana con el fin de conocer los sentidos atribuidos a las experiencias narradas por las investigadoras y la intertextualidad emergente luego de cada lectura. En este sentido, difundir las cartas generó correlatos en los cuales se vinculó la historia de los lectores y se reveló la experiencia que ocasiona leerse y reconocerse en las palabras del otro. 
Los marcos de referencia que se retomaron para orientar la elaboración de las cartas y el análisis de los resultados fueron el género epistolar (Agulló, 2002; Hintze y Zandanel, 2012) y la experiencia (Nancy y Pons, 2007; Álvarez et al., 2010; Mèlich, 2002; Larrosa, 2006). Estos constituyeron un punto de partida para reconocer las experiencias que circulan entre los maestros sobre la lectura y para suscitar la reflexión de quienes acompañan la educación infantil.

Por otro lado, el apartado de los resultados da cuenta de tres aspectos. Primero, de un acierto en la elección del enfoque metodológico para narrar y compartir la experiencia en torno a la lectura, lo que acentúa el lugar de los maestros y adultos como referentes del mundo para las nuevas generacio- nes. Segundo, cuando se alude a la lectura en el contexto escolar aparece una tensión entre la adquisición del código alfabético y la lectura como experiencia. Y tercero, se reconoce el género epistolar como recurso reflexivo y formativo en el oficio de los maestros y en el intercambio de saberes sobre nuestras prácticas.

Finalmente, se proponen algunas conclusiones que abren nuevas discusiones e invitan al uso de la literatura como experiencia en los espacios de educación infantil, donde la disposición de los maestros, sus memorias y experiencias literarias; la escucha de las motivaciones de los niños y las niñas y la oferta de posibilidades cumplen un papel fundamental.

\section{MARCOS DE REFERENCIA DE LA INVESTIGACIÓN}

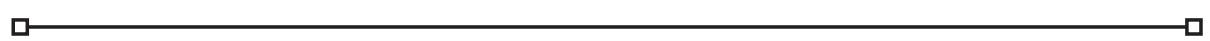

¿Cómo entendemos la experiencia y el género epistolar?

Los ejercicios investigativos representan una ocasión para la novedad. No obstante, hablar de "novedad" no pretende significar, en este contexto, un desconocimiento de aquello que ha antecedido. Alude, más bien, a un ejercicio de ida y vuelta: se recorre aquello que otros han tejido a raíz de búsquedas particulares y se renueva para situar y avanzar en algunas comprensiones en aquellos campos que se encuentran poco explorados y que, a su vez, se convierten en interés de análisis. Así, la novedad en este marco de referencias se comprende como aquello que algunos autores dieron a saber en los rastreos bibliográficos en relación con la experiencia y el género epistolar.

\section{La experiencia}

La experiencia permite nombrar, en palabras de Larrosa (2006), "eso que me pasa" (p. 44). No obstante, todo aquello que le pasa a un sujeto no siempre es experiencia. Al retomar algunas consideraciones sobre lo que se oye y lo que se escucha, se puede dilucidar un poco más lo que puede ser considerado o no experiencia, ya que, ante la amplitud del término, podría darse el caso de incluir en una misma categoría -experiencia- distintos modos de relación con acontecimientos en la vida de los sujetos.

Velásquez (2013) expone que hay una diferencia entre oír y escuchar. El oír se comprende en relación con las percepciones auditivas de las ondas sonoras. Por ello, que se cuente con un aparato auditivo funcional 
bastará para identificar las fuentes emisoras del sonido, el volumen, la sonoridad y la intensidad de aquellas ondas que se perciben; en tanto, podría decirse que este o aquel sujeto oye. El escuchar contiene el oír porque requiere de la percepción auditiva de las ondas sonoras y comprende una cosa más: tener el convencimiento de que en lo oído se dice "algo" (p.137). Todos los días pasan cosas, no obstante, no todas esas cosas que pasan se configuran en experiencia. Se comprende con estos enunciados que el campo en el que se sitúa la cuestión sale de lo objetivable, verificable o comprobable, posibilitando el abordaje con lo subjetivo y lo sensible.

"Eso que me pasa" sirve de expresión para relacionar y conjugar algunos principios que configuran la experiencia: la exterioridad, la subjetividad y el recorrido/ viaje. Acá se juega el adentro y el afuera, la distancia y la cercanía, lo otro y lo propio, las incertidumbres, las contingencias y las suspensiones entre lo que ocurre (exterior) y lo que se padece (subjetividad, recorrido/ viaje); por eso, la experiencia es "atención, escucha, apertura, disponibilidad, sensibilidad, vulnerabilidad, exposición" (Larrosa, 2006, p.64). En efecto, la exterioridad aborda el acontecimiento, aquello que no puede ser anticipado. En tanto, la exterioridad se sitúa en el borde de lo que el sujeto puede experimentar y que se escapa de su poder o de su voluntad. El prefijo ex sugiere que hay extranjeridad, novedad, no se sabe antes de... en tanto, se genera un reconocimiento $y$, como consecuencia, un encuentro que, por inesperado es impredecible en sus efectos y modos de vinculación.

Ahora bien, el aspecto subjetivo de la experiencia remite a que en el sujeto hay algo que acontece; ocurren transformacio- nes, afectaciones en lo que se es, en lo que se piensa, en lo que se sabe, en lo que se representa. En suma, la experiencia ocurre en el plano de los efectos subjetivos con la alteridad (con lo exterior y extranjero), con algo que no es un "yo"; es una construcción de sentidos, es un conjunto de remisiones que solo construye el sujeto de manera sensible frente a lo que es extraño (Nancy y Pons, 2007). Por ello, la idea de experiencia en relación con la transformación sostenida por Larrosa (2016), en la que no se tiene un punto de partida y un punto de llegada, en la que no hay un modelo de experiencia, ni fórmulas para lograrla, más bien, se trata de una agitación, en la que el sujeto padece un movimiento en la formación.

Por otro lado, estaría el viaje en la experiencia que, considerándolo como recorrido, implicaría un movimiento pendular. Esto es, hay una salida por parte del sujeto que deviene en transformación subjetiva $\mathrm{y}$, a su vez, hay algo que pasa desde la exterioridad hacia el sujeto. En tanto viaje, trayecto o recorrido, hay un encuentro que deja una huella, una traza sensible que tiene lugar en el sujeto que atiende eso que le pasa/que padece, eso que se permite escuchar, vivir, padecer y que deja una marca.

Con lo anterior, la experiencia permite crear un "tiempo otro" que se sale del significado de la temporalidad cronológica y expone al sujeto a la sensibilidad. Es una abstracción de lo cotidiano en la que tiene lugar el acontecimiento que es cargado por el significante de experiencia. Algunos investigadores (Álvarez et al. 2010) proponen que, si bien la experiencia "abarca el sentido de la novedad, lo trasciende para articularse con la idea de la formación como relato y de la finitud en tanto condición inherente al ser humano" (p. 29), considerando que no 
se trata solo de aquello que sucede, sino que el sujeto tiene la capacidad para reconocer un modo de ser, de estar y de posicionarse frente a la vida y de saberse humano. En los referentes más destacados, los autores convocan la propuesta de Mèlich (2002), mostrando cómo la experiencia le posibilita al ser humano reconocer su condición de finitud, lo que genera la construcción de un saber que habilita a encarar algunas vicisitudes de la cotidianidad, sin que ello sea un saber prescriptivo o un modelo para la solución de problemas. En esta línea discursiva, la experiencia acontece en el caos, cuando hay una agitación en los sujetos, y no en la pasividad de lo que se ha convertido en natural o neutral. Por esto:

La experiencia como aquello que nos pasa y se padece, tiene el carácter de acontecimiento, de ruptura, de discontinuidad, de suceso que deja huella, de transformación que puede narrarse y convertirse en objeto de representación de algo que ha pasado por el cuerpo, que ha sido vivido y que se actualiza a través del relato como acto de rememoración. (Álvarez et al., 2010, p.37)

Se resalta la palabra narrarse, en el sentido de evocación de la memoria, de aquello que deja huella en un sujeto y que hace parte de su biografización, de aquello a lo que se vuelve para ser destacado, que no se elimina del registro mental y que, con el lenguaje, puede ser transformado, resignificado $y$, por lo tanto, es relevante en el trayecto de vida. Con esto, la experiencia es un modo de constitución de subjetividades y con ello, un acto formativo -performativo de cómo se le da forma a la vida.

\section{El género epistolar.}

Por otro lado, elegir los modos de comunicación también va a significar el tipo de relación que el emisor pretende establecer con el receptor de un mensaje. Tal vez, pudiera sugerirse que elegir el portador de texto

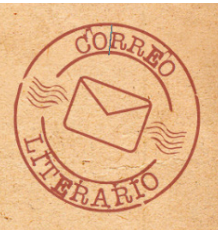
responde a asuntos formales del contexto de interacción comunicativa. No obstante, en este escenario se estima que los modos en que se decide transmitir unas ideas implican tanto lo técnico y estructural, como asuntos que abarcan los vínculos entre los sujetos.

A continuación, se presentan algunas consideraciones sobre el género epistolar, comprendiendo que elegir un portador de texto, un género de escritura y el lenguaje que implementamos en un escenario comunicativo no es un asunto neutral o desprevenido.

Como punto de partida, se coincide con Delory-Momberger (2015) en pensar que el hombre, como homo narrans, "ser narrador", es la única especie que se narra a sí misma y crea historias, lo que involucra una narración consigo mismo y con los demás. Hablar de epístola o de carta es, en todo caso, hablar de la comunicación, de aquello que los sujetos quieren narrar. Pensar las cartas como una forma de comunicación a distancia no es la única definición posible, ya que sería reducir sus implicaciones y efecto en la interacción comunicativa.

Agulló (2002) indica que, considerando el propósito de las cartas, estas pueden ser distinguidas en el marco de lo público y lo privado. Se encuentran aquellas misivas que son confidenciales o eruditas, escritas para ser publicadas o las propiamente literarias. A su vez, no sería posible enmarcar la producción de las cartas en un campo particular. Estas pueden ser utilizadas en obras de distinta naturaleza. Por eso, aunque se reco- 
nocen de forma amplia producciones literarias en género epistolar, también se rastrean cartas políticas, religiosas y filosóficas con mucho protagonismo.

De manera particular, se resalta que esta tipología textual, al ser producida la mayoría de las veces en primera persona, evidencia la subjetividad de quien la emite, lo que permite destacar dos aspectos importantes. Primero, la autenticidad del mensaje y la responsabilidad que recae sobre el sujeto productor del mensaje. Segundo, la nombrada "concientización histórica" (Hintze y Zandanel, 2012, p. 14, citando a Weintraub, 1975 , p. 821), porque quien escribe presenta en lo dicho y no dicho las condiciones o posibilidades de producción históricas, sociales y culturales que sólo el sujeto con disposición a dirigirse a otro puede representar mediante la palabra escrita.

Desde luego, se podría concluir que los discursos dispuestos en las cartas son, retomando algunas referencias de Foucault (1999), modos de escritura de sí con la capacidad de dejar al descubierto al uno ante la mirada del otro.

La carta torna manifiesta la capacidad de quien escribe de mostrarse ante el otro, de explicitar sus ideas y su mundo interior, de despojarse ante la mirada del destinatario a los efectos de permitirle un conocimiento más acabado de sí mismo y, como consecuencia, simultáneamente, opera sobre el destinatario en esa posibilidad de apertura al conocimiento del otro (Hintze y Zandanel, 2012, p. 16).

Desde estas concepciones, las cartas se resignifican en el contexto académico como un modo de escritura con apertura a lo dialógico. Se presentan como portadores discursivos que develan la historicidad y el reconocimiento de los sujetos productores de saber en sus prácticas, en la cotidianidad y en la experiencia. Además, posibilitan la toma de conciencia (volver a lo vivido), seleccionando aquello que se quiere transmitir y haciéndolo propio.

Ahora bien, el recorrido por estos apartados permite referenciar algunas consideraciones y orientaciones conceptuales y teóricas que se tuvieron en cuenta en la investigación. La construcción de estos lentes posibilita, sobre todo, poner de manifiesto los marcos de referencia e interpretación en la innovación didáctica, que se convierten en esa selección de lo que otros han hecho, con el propósito de ser capitalizado en la atribución de nuevos sentidos y miradas cuando se intenta abordar La literatura infantil como experiencia en la educación inicial.

\section{Presentación y discusión de los Resultados}

A continuación, enunciamos los principales resultados y hallazgos de la investigación que contribuyen a la reflexión sobre el acompañamiento, la acogida y la experiencia de los niños y las niñas en la educación inicial. Para desarrollar la discusión se proponen tres líneas: la primera hace referencia al aporte de la investigación biográfico narrativa para considerar el sentido que tiene volver sobre la propia historia para hacer lugar a aquello que, en este caso, se configuró como una experiencia literaria para las investigadoras, lo que dio lugar a una relación cercana con los libros y la práctica de 
lectura. La segunda línea se refiere a las tensiones y desafíos que supone la enseñanza de la lectura en la escuela, donde es preciso considerar a los niños y las niñas como portadores de un saber previo que han construi- do en los espacios de socialización familiar y comunitaria. La tercera línea sitúa al género epistolar como una forma de expresión que permite la reflexión y formación de los maestros de educación inicial.

\section{LA INVESTIGACIÓN BIOGRÁFICA Y NARRATIVA: “UN ACONTECIMIENTO DEL SER"}

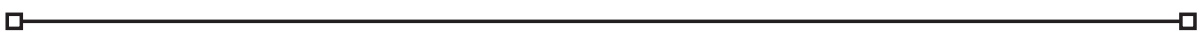

Al mirarnos uno al otro, dos mundos distintos se reflejan en nuestras pupilas (Bajtín, 1995)

El epígrafe comparte una noción de lo que significa la investigación biográfica y narrativa en el marco de esta investigación; compartir el mundo con otros para reconocer las diferencias y el reflejo de aquello que nos identifica. Bajtín (1995) enuncia el "acto ético" para referirse a la tensión existente del deber ser que proviene de la presencia de otro, lo cual trae responsabilidades y consecuencias producto de ese encuentro. Según el autor, el oyente/lector es también hablante y productor de sentidos e interpretaciones, lo que apareció de forma reiterada en las cartas que fueron compartidas con los maestros que participaron de la propuesta.

Escribimos cartas de maestros para maestros que ilustraron imágenes sobre aquellos eventos que desde la infancia configuraron una relación con los libros, las historias, las vidas narradas de otros, que, en últimas, representan nuestras propias vidas; aquellas que imaginamos y que nos permitieron experimentar el mundo de otras maneras. Como lo expresa Montero (2003), "tú te vives dentro de esas existencias" (p.21), dentro de esas historias ajenas que se vuelven parte de la propia experiencia con la lectura en el mismo sentido. En concordancia, Benjamin (2009) expresa que "el narrador toma lo que narra de la experiencia; la suya propia o la transmitida, la toma a su vez en experiencias de aquellos que escuchan su historia" (p.56).

Por esta razón, decidimos escribir cartas que narran cómo cuatro maestras encuentran en la lectura una posibilidad para entender situaciones del mundo, aquel que se desenvuelve actualmente en la escuela y pone en relieve una preocupación latente: las exigencias institucionales y sociales para que los niños lean convencionalmente antes de terminar su primer grado escolar. En palabras de Vargas Llosa (como se citó en Montero, 2003), "el proceso de creación narrativa es la transformación de un demonio en un tema" (p. 71), y nuestro demonio se situó en la ansiedad por alcanzar los objetivos que impone la escuela en torno a la lectura. Este se convirtió en el tema explorado en nuestras cartas. De esta forma, se despliega el encuentro con otros seres. Un ejemplo lo constituyen los siguientes fragmentos:

Aún no tengo palabras para decirte las caricias que recibo cuando me observas, pero sí creo que alcanzas a intuir lo importante que me siento cuando intentas descifrar lo que me pasa en ese instante. (Carta 2) 
Profesora Maryorie, han pasado varios años desde la última vez que nos vimos y hablamos, cada una emprendió un camino diferente, nuestros caminos se bifurcaron, se distanciaron, pero al final, hubo algo que terminaría uniéndose allí, donde todo inició, en el salón de clase. Por eso hoy quiero expresarte estas palabras a ti y a tu recuerdo latente. (Carta 3)

Sé que no todos los compañeros de mi clase contaron con la ayuda de sus padres, eso me hacía sentir respaldada, como si el mundo entero pudiera atacarme porque yo los tenía a ustedes; pero al mismo tiempo - en muchas ocasiones-, me hizo sentir débil, y me hacía pensar que nunca iba a estar lista para hacer las cosas por mi propia cuenta. (Carta 5)

En los fragmentos se advierte lo que Benjamin (2009) expresa de la narración, aquella potencia que mantiene su fuerza acumulada y es capaz de desplegarse aún después de largo tiempo. Disponer a otros los acontecimientos que precisaron la experiencia literaria de las investigadoras implicó encontrarse con los rostros que acompañan, aún hoy, la educación inicial: maestros, padres, madres, amigos, quienes se convierten en referentes del mundo para que los niños configuren su propia existencia. Esto es 1o que se despliega en las cartas como un acontecimiento ético, estético y de experiencia que aportó una mirada de nosotros mismos, en tanto seres nombrados, reconocidos, acogidos. Esta relación inaugural y permanente con los pares y adultos nos dotó de palabras y experiencias para hacernos un lugar en el mundo y transformó en algún sentido nuestra experiencia con la literatura.

En esta línea, los personajes de la correspondencia son: un niño que propone estrategias a una maestra para la aproximación a la lectura, una niña que escapa de la rutina escolar para encontrarse con un libro que llama su atención, un bebé que lee las situaciones de su vida cotidiana; una joven que rememora la ficción de sus padres lectores, una maestra que revela las angustias vividas en la escuela y un libro que es acariciado por las manos de pequeños lectores.

Estos personajes, reales o producto de la ficción del recuerdo, denotan experiencias que cobran sentido para el narrador, las mismas que son interpeladas por otros a partir de su propia experiencia. Lejeune (1991) alude al pacto biográfico, el cual funciona como una especie de contrato en la que el autor abre las puertas hacia la intimidad de su propia historia para los lectores, quienes continúan con el proceso de configuración y composición, a partir de su propia experiencia. Esto cobra especial sentido cuando la lectura, la escritura, la conversación y la reflexión individual y colectiva se configuraron en un escenario para la reflexión durante la investigación. Según Dávila (2012), esto se convierte en materia prima para reconocer los saberes que se construyen a partir de la experiencia pedagógica, lo que implica tomar decisiones y resignificar caminos en el oficio de educar.

De esta forma, quienes leyeron las cartas y las escritoras, en calidad de investigadoras, sentimos conmoción sobre las experiencias de vida relatadas, las cuales permitieron una reflexión sobre nuestras prácticas actuales como maestras y nos dispusieron imágenes sobre los sentidos que la lectura como experiencia puede representar en la cotidianidad de la escuela. En los relatos de los destinatarios de los mensajes epistolares se identifica aquello que se puede hacer con la correspondencia. Por ejemplo, "las experiencias 
no siempre están en el aula y un libro o una lectura se puede transversalizar con las diferentes dimensiones y en los proyectos que se desarrollan con los niños" (C3DT2).

Así mismo, aparecen ideas en torno a las acciones frente a la lectura. Se referencia que son los adultos los que persuaden la aproximación de los niños a los libros. Así, una de las maestras destinataria de las car- tas enuncia: "si nosotros leemos y tenemos ese hábito, posiblemente nuestros hijos $\mathrm{y}$ nuestros estudiantes también lo van a adquirir" (C4DB5). Esta apreciación alude a las actitudes y acciones que los adultos tienen frente a los niños y que podrían representar referencias para ser en el mundo; es decir, para replicar condiciones del mundo de los adultos que terminan incidiendo en las motivaciones de los más pequeños.

\section{LA ENSEÑANZA de LA LECTURA: Un DESAFío PARA LA ESCUELA}

\section{Figura 1}

Fragmento de carta 2. Sebastián Cardona

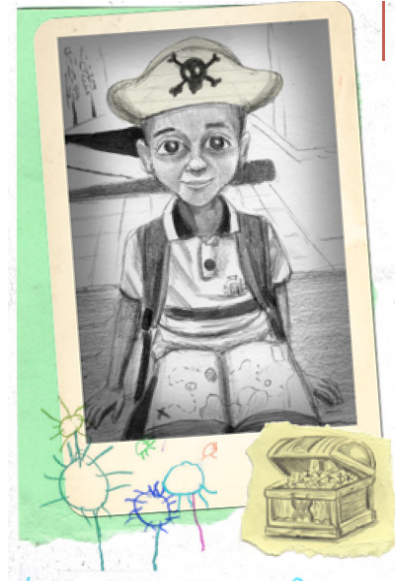

Al hacer un recorrido por las temáticas que se abordan en las cartas, la primera, escrita por un niño de 8 años, sugiere estrategias desde la perspectiva infantil para motivar la lectura en los entornos escolares. Sebastián acude a sus experiencias previas para decirle a las maestras: "a los niños no les gusta leer porque ellos quieren leer lo que les gusta". Esta afirmación da cuenta de que la elección de las metodologías y tipos de texto que se abordan en la escuela son seleccionadas por los maestros y no por los niños, quienes también pueden aportar temas de interés sobre lo que quieren conocer a través de formatos que no son convencionales

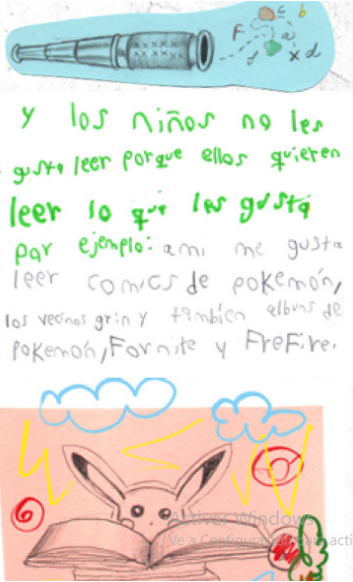

en la aproximación a la lectura. En esta experiencia particular, Sebastián prefiere leer "comics de Pokemón, Fornite y Frefire". Estos formatos hacen parte de la cultura digital a la que pertenece y se plantea como desafío para la enseñanza en la escuela, máxime para los tiempos actuales en los que la pandemia mundial ha obligado a transformar las prácticas de enseñanza y a incorporar los medios virtuales para el encuentro con los estudiantes.

De esta forma, acudir a nuevos formatos narrativos, diferentes a los libros de texto o guías de estudio, es menester para que las 
metodologías que propone la escuela en la alfabetización inicial y la enseñanza de la lectura motiven la participación de los niños, quienes cuentan con un acervo de experiencias previas en la interacción con los entornos digitales. La riqueza y diversidad de los géneros discursivos es inmensa, porque las posibilidades de la actividad humana son inagotables y porque en cada esfera de la praxis existe todo un repertorio de géneros discursivos que se diferencia y crece a medida que se desarrolla y se complica la esfera misma (Bajtín, 1995).

La mayoría de los estudiantes que llegan a la escuela han tenido un contacto previo con el mundo digital; celulares, tablets, computadores, iPads, entre otros, representan el acceso a la virtualidad y a un sistema de información que no es ajeno al mundo infantil, por ello, "es importante recordar que los niños construyen la función social y comunicativa de la lengua en una interacción permanente con diferentes tipos de textos" (Hurtado, 2016). De esta forma, la escuela tiene un campo en el cual es posible familiarizarse con las características de la sociedad en la que se inscribe e incorporar recursos que sean próximos a la experiencia infantil y a los contextos de comunicación propios de su cultura. Estas acciones están en consonancia con los fines de la educación en Colombia:

El acceso al conocimiento, la ciencia, la técnica y demás bienes y valores de la cultura, el fomento de la investigación y el estímulo a la creación artística en sus diferentes manifestaciones; la promoción en la persona y en la sociedad de la capacidad para crear, investigar, adoptar la tecnología que se requiere en los procesos de desarrollo del país (Ley 115, 1994)
Por otro lado, la carta de Sebastián advierte que la enseñanza de la lectura se basa en métodos que centran su interés en la apropiación del código lector más que en el disfrute de este proceso, es por esto que dice "diles cómo suena la letra... así que digas la $l$ con la a suena [la]". El método silábico que reproduce Sebastián en su carta carece de significado en el contexto de la lectura, separa las palabras de su contexto comunicativo y privilegia el nombre de las letras sobre el sentido del acto comunicativo o, en otras palabras, en el problema retórico (Cassany, 2019). La literatura como experiencia precisa habitar ese "territorio de lo imaginario" (Montes, 1999, p. 16) en el cual aparecen los textos para presentar a los niños un abanico de posibilidades donde puedan crear y representar nuevas realidades. La lectura, desde esta perspectiva, no insta a preguntas por las moralejas de las narraciones y no centra su atención en la extracción de palabras que transcriben y repiten los niños sin ningún sentido. Al contrario, dispone ficciones e imágenes para que ellos lean el mundo.

Como resultado de la investigación se puede pensar que la literatura aporta a la infancia representaciones de la realidad y configura algunas actuaciones de los niños en los espacios sociales. Canclini (2010) ofrece una mirada al respecto cuando advierte el lugar de los diversos géneros literarios en la configuración de los imaginarios sobre la ciudad. Se refiere a las leyendas, mitos, pinturas y películas que recrean la forma en la que las personas se hacen una idea de la misma, configurando un imaginario colectivo del que "seleccionamos fragmentos de relatos, y los combinamos en nuestro grupo, en nuestra propia persona, para armar una visión que nos deje un poco más tranquilos y ubicados" (Pág.95) 
Así, leer es un acto que no debe disputarse un terreno con los medios de comunicación digital y virtual en el que están inmersos los niños, al contrario, se considera que la lectura digital y los portadores de texto que tradicionalmente se han dispuesto en nuestros contextos escolares, familiares y sociales (libros impresos, revistas impresas, entre otros) pueden aportar a la construcción del pensamiento crítico, a la aproximación de la experiencia humana y al sentido poético que imprime representar el mundo a partir de la mirada de otros. Se trata de lo que Petit (2008) anuncia como disponibilidad, recibimiento y presencialidad de calidad que considere a los niños como sujetos.

\section{EL GÉNERO EPISTOLAR COMO RECURSO REFLEXIVO Y FORMATIVO EN LA PRÁCTICA DE LOS MAESTROS}

口

\section{Figura 2}

\section{Diseño de la correspondencia}

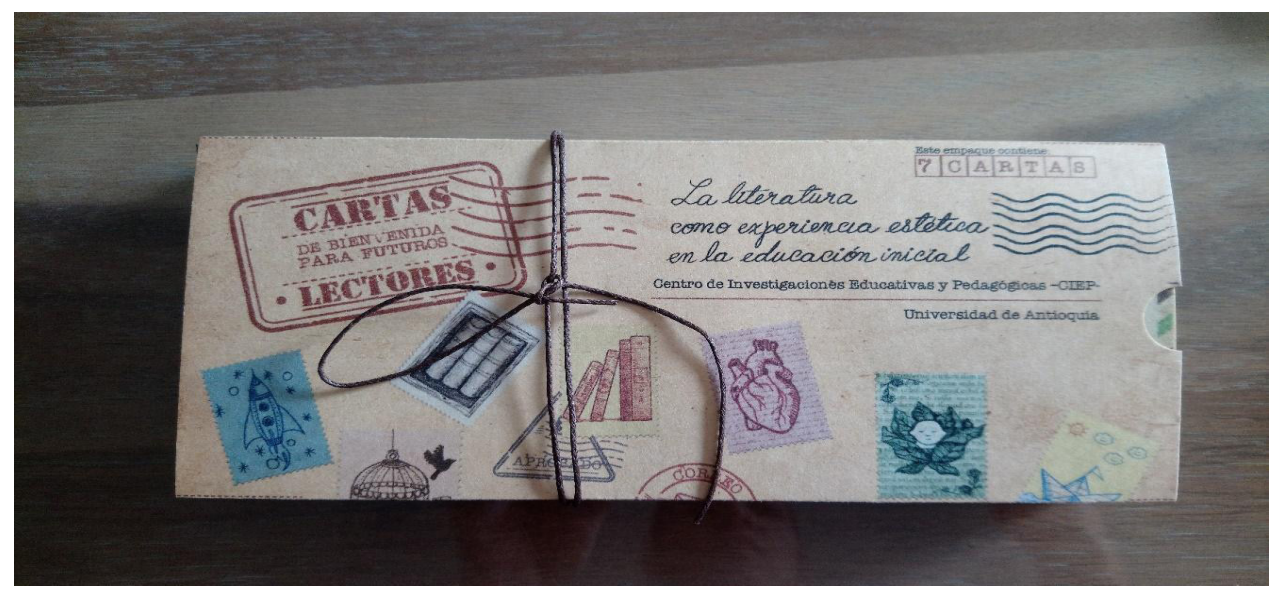

A continuación, disponemos de algunos relatos de las personas entrevistadas que muestran con un tono conversacional lo que significó para las maestras la lectura de la correspondencia y lo que representan estos nuevos sentidos para las investigadoras, en tanto maestras de escuela, que acompañan el inicio del proceso lector con los niños. Por eso, es una reflexión que funciona como boomerang o péndulo. Se escribieron relatos de experiencia, se compartieron con las maestras y esto permitió que ampliarán el sentido e interpretación de las cartas. Al transcribir las entrevistas nos llega una in- formación que no anticipamos, se devuelven comprensiones, nuevas miradas frente a la correspondencia y rasgos de los efectos que estas lecturas pueden alcanzar. Escribir cartas es una manera de escribir diálogos entre el investigador y los participantes, es otra fuente de datos en la investigación narrativa [...] escribir cartas es una manera de ofrecer interpretaciones narrativas provisionales y de responder a ellas (Connelly y Clandinin, 1995, p.27)

Apelar a la voz de las investigadoras desde las experiencias personales y profe- 
sionales relacionadas con la lectura significó un acierto para la investigación, en tanto ofreció una mirada en retrospectiva de los momentos específicos en que un adulto nos habilitó como lectoras y nos invitó a reconocer el mundo desde otra perspectiva. Según Montero (2003), "uno escribe para expresarse, pero también para mirarse en un espejo y poder reconocerse y entenderse" (p.82). Escribir cartas que retoman anécdotas sobre nuestra relación con la lectura permitió reconocer que esta práctica es una elección que antes ha estado mediada por referentes adultos que persuaden en su condición de representantes del mundo frente a los niños. Así, frente al lugar de los adultos, los maestros entrevistados señalan que:

Uno termina con el sentimiento de la responsabilidad mucho más arraigado. (C3DT2) Tengo en mis manos cada año el futuro de mi país, y si desde el aula, con la literatura, puedo cambiar sus vidas mostrando nuevos caminos, lo debo hacer. (C3DT2)

[Me invita] A ser un agente motivacional en mis niños para la lectura. (C3DT3)

Con estas apreciaciones se denota al adulto formador como fuente de experiencias que se pueden ofrecer a los niños en su condición de lectores, no solo de textos escritos, sino también de actitudes y acciones que son percibidas por quienes comparten el entorno escolar. Esta interacción entre maestros y niños puede significar una suerte de dispositivo para la motivación a la lectura. También, se identifica que se alcanzó el propósito implícito de las cartas, donde se pretendía compartir con los maestros las experiencias de la vida cotidiana que están relacionadas con la lectura.
A su vez, exponer el contenido de las cartas abrió el camino para escuchar nuestros relatos en la voz de otros, significó apreciar la experiencia desde "afuera", es decir, como oyentes y no solo como autores de las cartas. Bajtín (1995) expresa que "el oyente se convierte en hablante [...] tarde o temprano lo escuchado y lo comprendido activamente resurgirá en los discursos posteriores o en la conducta del oyente" (p.8). Así, las cartas dirigidas a los maestros resultaron en un recurso de identificación para pensar las prácticas pedagógicas en la escuela $\mathrm{y}$, por tanto, una posibilidad para reflexionar sobre la cotidianidad escolar que, en ocasiones, pasa desapercibida ante las múltiples responsabilidades y premisas que impone el ejercicio profesional docente. Al respecto, los maestros exponen:

Me identifico con la carta en el sentido que mi deseo es que mis niños me recuerden con el mayor cariño desde las perspectivas de todas las personas que mencionan en la carta: la de los padres, la de la muchacha ya siendo estudiante y también cuando ella evoca su época de niñez. También sentimientos muy encontrados, porque yo estoy pasando por una situación similar a la del personaje de la carta; entonces me generó mucha empatía. (C3DT4)

Esta identificación resulta de generar espacios con los maestros para poner en común las experiencias de la vida infantil en torno a la lectura y que representan un entramado de ideas acerca de las formas en las que se enseña, se aprende o se es adulto. Las cartas, al ser una especie de conversación escrita dirigida a los maestros, en la cual se apela a la experiencia -esto me pasó- promueven una confianza y empatía para que compartan sus condiciones personales en torno a un tema que es de interés pedagó- 
gico y colectivo: la enseñanza de la lectura en la escuela y los retos, prejuicios y miedos que se generan con esta responsabilidad. Por tanto, el género epistolar aparece como una posibilidad para reflexionar sobre las prác- ticas pedagógicas de los maestros y para ilustrar formas en la que podría develarse el ejercicio formativo en la vida cotidiana de la escuela.

\section{Conclusiones}

En los programas de formación continua de maestros de primera infancia, preescolar y básica primaria, en nuestro contexto, identificamos que existen múltiples apuestas, orientaciones y caminos para considerar las prácticas pedagógicas de los maestros que ejercen en los ámbitos público y privado. Entre ellas, se destaca la producción de cuadernillos, guías, protocolos de planeación que indican el paso a paso que conlleva a la implementación exitosa de una propuesta educativa con niños y niñas. No obstante, los mismos maestros reconocemos que esas orientaciones descontextualizadas, donde no se reconocen las particularidades de los grupos poblacionales, los contextos y los territorios, fracasan al intentar estandarizar y regular la práctica con los estudiantes.

Este recorrido de diseño, formulación y divulgación de las cartas destinadas a compartir el relato (auto)biográfico con otros maestros y las conversaciones suscitadas alrededor del contenido de las epístolas, evidencian la importancia del trabajo en red y en colectivos que se dispongan para la reflexión sobre el oficio del maestro en condiciones situadas. Además, pone de manifiesto que el discurso experto o del deber ser constituye una tensión frente al oficio de artesano (De Tezanos, 1986), del uno a uno que se construye en la cotidianidad de la relación pedagógica.
La escritura de las cartas y el diálogo con los maestros nos muestra que la acción performativa (Butler, 2004) del que se dispone como enseñante se configura a la luz de las experiencias propias y ajenas. La interpelación que sentimos cuando otros narran sus interacciones con estudiantes, familias o acudientes, exponen los puntos en común y también los detalles y minucias que enmarcan el proyecto formativo que se gesta, donde la literatura infantil ha tenido un lugar en los modos de convocar el encuentro con silencios, pausas, provocaciones o recuerdos que se suman al andamiaje de relatos que circulan entre niños y adultos.

Proponemos algunas líneas que pueden abrirse con esta investigación: la formación y ejercicio profesional de los maestros; la relación de maestros y adultos de cara a la educación de las infancias; el valor del reconocimiento de los contextos y de la escucha a los niños y las niñas como aporte para la interacción pedagógica y la literatura infantil como punto de encuentro entre los niños y los adultos en la construcción que comparten del mundo.

Por último, consideramos que es necesario habilitar nuevas preguntas y escenarios para los maestros, en los que puedan narrar, compartir y reflexionar sobre sus experiencias. En este sentido, el enfoque (auto)biográfico narrativo posibilita comprensiones 
sobre eso que les pasa y lo que acontece en los entornos educativos con relación a los niños y las niñas. Desde este enfoque, el saber no refiere solo a los conocimientos disciplinares en los que se forman los maestros, sino a su posición histórica, personal y subjetiva.

\section{REFERENCIAS}

Agulló, (2002). El género epistolar: de las «cartas filológicas» del murciano Francisco Cascales al correo electrónico. En: Martínez, J. Cultura, economía y desarrollo en Lorca en el alba del siglo XXI: actas del XXXVII Congreso Internacional de la Asociación Europea de Profesores de Español, Lorca, 21-26 de julio del 2002. EDITUM.

Álvarez, R., y Góngora y Fernández, A. (2010). Elementos de literatura filosófica, perceptiva e histórico-crítica con aplicación a la española. Madrid: Biblioteca Virtual Miguel de Cervantes. http:// www.cervantesvirtual.com/nd/ark:/59851/bmcv7007

Álvarez, E., Areiza, C., Díaz, J.., Leal, S., Parra, M, Zuluaga, G., y Giraldo, A. (2010). Infancia y finitud: una lectura fenomenológico-hermenéutica a los relatos de formación de un grupo de niños y niñas con cáncer [Trabajo de pregrado]. Universidad de Antioquia, Colombia

Bajtín, M. (1995). Autor y personaje en la actividad estética. Estética de la creación verbal. México: Siglo XXI.

Butler, J. (2004). Lenguaje, poder e identidad. Editorial Síntesis.

Canal Capital. (2021, 13 de abril). Carolina Sanín entrevista a Yolanda Reyes [Video] YouTube. https://www.youtube.com/watch?v=GcQLIPxnivA\&ab_channel=CanalCapitalBogota

Cassany, D. (2019). Describir el escribir. Cómo se aprende a escribir. España: Editorial Planeta.

Canclini, N. G. (2010). Imaginarios Urbanos. Buenos Aires: Editorial Universitaria Buenos Aires.

Congreso de la República de Colombia (1994, 15 de febrero). Ley 115. Colombia

Connelly, M., y Clandinin, J. (1995). Relatos de experiencia e investigación educativa. En J. Larrosa et al. (comps.), Déjame que te cuente. Ensayos sobre narrativa y educación (11-59). Barcelona: Laertes/ Psicopedagogía.

Colomer, T. (1998). La formación del lector literario. Narrativa infantil y juvenil actual. Madrid: Fundación Germán Sánchez Ruipérez.

Dávila, P. (2012). La documentación narrativa de experiencias pedagógicas. Una estrategia de reposicionamiento de saberes, conocimientos y actores en el campo de la formación docente. Revista Educación y Pedagogía, 23(61), 145-155.

Delory-Momberger, C. (2015). El relato de sí como hecho antropológico En: Gabriel Murillo (Comp.), Narrativas de experiencia en educación y pedagogía de la memoria. http://ayura.udea. edu.co:8080/jspui/bitstream/123456789/1117/1/CA0654.pdf 
De Tezanos, A. (1986). Maestros, artesanos, intelectuales. Bogotá: Universidad Pedagógica Nacional.

Hintze, G., y Zandanel, M. A. (2012). Algunas nociones sobre el género epistolar a propósito de las cartas de Francisco Romero. Some notions on the epistolary genre based on the analyses of Francisco Romero's letters. Cuyo, 29.

Hurtado, R. (2016). Enseñanza de la lectura y la escritura en la educación preescolar y primaria. Medellín-Colombia: Universidad de Antioquia.

Foucault, M. (1999). Estética, ética y hermenéutica. Buenos Aires: Ediciones Paidós Ibérica.

Nancy, J., \& Pons, H. (2007). A la escucha. Buenos Aires: Amorrortu.

Larrosa, J. (2003). La clase de literatura. En: La experiencia de la lectura estudios sobre literatura y formación. México: Fondo de Cultura Económica.

Larrosa, J. (2006). Experiencia y narración. Revista Educación y Pedagogía, 18.

Lejeune, Ph. (1991). El pacto autobiográfico. Suplementos Anthropos, 29, diciembre, 47-81.

http://semioticaderedes-carlon.com/wp-content/uploads/2018/04/Lejeune.pdf

Mèlich, J. (2002). Filosofía de la finitud. Barcelona: Herder

Ministerio de Educación Nacional (2014). Serie de orientaciones pedagógicas para la educación inicial en el marco de la atención integral. La literatura en la educación inicial, Documento $N^{\circ} 23$.

Montero, R. (2003). La loca de la casa. España: Alfaguara.

Ocaña, A. (2010). La escritura autobiográfica y su repercusión en el ámbito educativo. Josefina Aldecoa como ejemplo de autobiografía y docencia (Tesis doctoral). Universidad Nacional de educación a distancia, Facultad de Filología.

Petit, M. (2000). Elogio del encuentro. Congreso Mundial de IBBY (International Board on Books for Young People). Cartagena de Indias, 18-22 de septiembre

Petit, M. (2008). Una infancia en el país de los libros. España: Editorial Océano.

Petit, M. (2009). El arte de la lectura en tiempos de crisis. España: Editorial Océano.

Rodari, G. (1980). La imaginación en la literatura infantil. Perspectiva Escolar, 43, 9-13.

Soto, G. (1996) La creación del contexto: función y estructura del género epistolar. Revista ONOMAZEIN, 1, 156-166.

Velásquez, C. (2013). La función de la escucha en el ámbito escolar. En: M. Ramírez. Conductas de riesgo en el ámbito escolar. (135-150). Medellín, Colombia: Nueva Escuela Lacaniana. NEL Medellín. 